\section{The T-box transcription factor Eomes/Tbr2 regulates neurogenesis in the cortical subventricular zone}

\author{
Sebastian J. Arnold, ${ }^{1,5}$ Guo-Jen Huang, 2,5 \\ Amanda F.P. Cheung, ${ }^{3}$ Takumi Era, ${ }^{4}$ \\ Shin-Ichi Nishikawa, ${ }^{4}$ Elizabeth K. Bikoff, ${ }^{1}$ \\ Zoltán Molnár, ${ }^{3}$ Elizabeth J. Robertson, ${ }^{1,6}$ and \\ Matthias Groszer ${ }^{2,6,7}$
}

\begin{abstract}
${ }^{1}$ Sir William Dunn School of Pathology, University of Oxford, Oxford OX1 3RE, United Kingdom; ${ }^{2}$ Wellcome Trust Centre for Human Genetics, University of Oxford, Oxford OX3 7BN, United Kingdom; ${ }^{3}$ Department of Physiology, Anatomy and Genetics, University of Oxford, Oxford OX1 3QX, United Kingdom; ${ }^{4}$ Laboratory for Stem Cell Biology, Riken Centre for Developmental Biology, Chuo-ku, Kobe 650-0047, Japan
\end{abstract}

The embryonic subventricular zone (SVZ) is a critical site for generating cortical projection neurons; however, molecular mechanisms regulating neurogenesis specifically in the SVZ are largely unknown. The transcription factor Eomes/Tbr2 is transiently expressed in cortical SVZ progenitor cells. Here we demonstrate that conditional inactivation of Tbr2 during early brain development causes microcephaly and severe behavioral deficits. In Tbr2 mutants the number of SVZ progenitor cells is reduced and the differentiation of upper cortical layer neurons is disturbed. Neurogenesis in the adult dentate gyrus but not the subependymal zone is abolished. These studies establish Tbr2 as a key regulator of neurogenesis in the SVZ.

Supplemental material is available at http://www.genesdev.org.

Received February 11, 2008; revised version accepted July 8, 2008.

In mammals highly diverse populations of neurons are organized into the complex structure of the six-layered neocortex. Projection neurons populating each layer are generated sequentially in proliferative zones adjacent to the ventricle in an "inside-out" fashion (Rakic 1974). In early neurogenesis, radial glial cells (RG) in the ventricular zone (VZ) generate mainly lower-layer pyramidal cortical neurons through asymmetric divisions directly at the apical surface of the ventricle. As neurogenesis proceeds, RGs additionally generate intermediate progenitor cells (IPCs) that undergo symmetrical divisions predominantly in the subventricular zone (SVZ) (Haubensak et al. 2004; Noctor et al. 2004), giving rise to neurons

[Keywords: Eomesodermin; Tbr2; neuronal progenitor cells; SVZ; brain size]

${ }^{5}$ These authors contributed equally to this work.

${ }^{6}$ These authors contributed equally to this work.

${ }^{7}$ Corresponding author.

E-MAIL Matthias.Groszer@well.ox.ac.uk; FAX 44-1865-287533.

Article is online at http://www.genesdev.org/cgi/doi/10.1101/gad.475408. destined for upper cortical layers (Wu et al. 2005). Hence, the early embryonic SVZ contains at least two distinct neural cell populations: migrating neurons and IPCs (Tarabykin et al. 2001). The substantial enlargement of the SVZ and upper cortical layers in mammalian phylogeny suggests that IPC-derived neurons have markedly contributed to the evolutionary expansion of the cortex (Smart et al. 2002; Kriegstein et al. 2006). This view is supported by the absence of SVZ mitoses in the developing reptilian and avian dorsal cortex, which lack equivalent cortical layers II-IV (Cheung et al. 2007). The molecular mechanisms that specifically regulate proliferation and differentiation of IPCs are largely unknown. Few genes display predominant SVZ expression, notably subventricular-expressed transcript 1 (Svet1) (Tarabykin et al. 2001), the transcription factors cut-like 2 (Cux2) (Zimmer et al. 2004), and the T-box transcription factor Tbr2 (Englund et al. 2005). Expression of Svet1 and Cux2 appears to persist in IPC-derived upper cortical layer neurons, suggesting they represent SVZ markers for upper-layer progenitors (Molyneaux et al. 2007). This is consistent with recent studies demonstrating that Cux2 knockout mice display increased IPC proliferation and upper cortical layer thickness (Cubelos et al. 2007).

In contrast, Tbr2 is only transiently expressed during SVZ neurogenesis. Tbr2 expression initiates between embryonic day 10 (E10) and E12 in a few differentiated preplate neurons including Cajal-Retzius cells. Highest Tbr2 expression is detected between E12 and E16 in IPCs coincident with the peak of murine cortical neurogenesis and decays after E17 (Englund et al. 2005; Molyneaux et al. 2007). In humans a homozygous chromosomal translocation that disrupts Tbr2 expression is associated with microcephaly, polymicrogyria, corpus callosum (CC) agenesis, cognitive deficits, and severe motor delay with hypotonia (Baala et al. 2007). In mice Tbr2 is required for development of the trophectoderm and during germ layer formation, leading to embryonic death before onset of neurogenesis (Russ et al. 2000; Arnold et al. 2008). To study Tbr2 function during brain development we conditionally inactivated Tbr2 in the CNS.

\section{Results and Discussion}

Animals lacking Tbr2 expression in the CNS were generated by crossing Tbr2/Eomes ${ }^{\mathrm{CA} /+}$;Sox1 Cre to Tbr2/ Eomes ${ }^{\mathrm{CA} / \mathrm{CA}}$ mice (Arnold et al. 2008). Soxl Cre mice (Takashima et al. 2007) strongly express Cre throughout the neural tube from E9.5 before the onset of Tbr2 expression in the CNS at E10.5 (Bulfone et al. 1999). As a control, Sox1 Cre mice crossed to the R26R reporter strain activate LacZ expression throughout the neural tube at E10.5 (Supplemental Fig. 1A). Excision of the conditional allele in E13.5 brains was confirmed by RTPCR and Western blots (Supplemental Fig. 1B,C).

Mutant animals (Tbr2/Eomes ${ }^{\mathrm{CA} / \mathrm{CA}}$; Sox 1 Cre) were viable and fertile but displayed severe behavioral abnormalities. Mutants were readily identifiable due to their enhanced aggressiveness upon handling. Breeding of mutant females ( $n=4$, eight litters) to wild-type males and vice versa $(n=2$, four litters) gave viable offspring; however, pups were invariantly subject to infanticide at birth. If mutant males were removed, offspring survived 

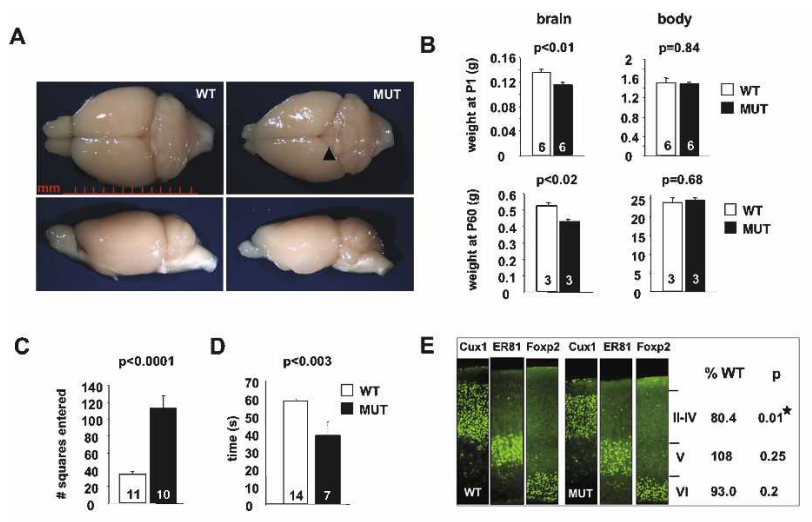

$\mathbf{F}$
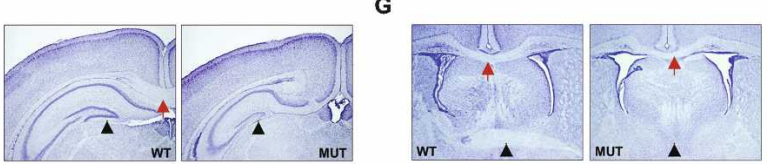

Figure 1. CNS-specific Tbr2 inactivation causes microcephaly and behavioral abnormalities. $(A)$ Dorsal and lateral views show a significantly reduced size of the cortex (note the more exposed tectum, arrowhead) and $\mathrm{OB}$ in adult mutant brains. $(B)$ Brain, but not body, weight is significantly decreased at $\mathrm{P} 1$ and $\mathrm{P} 60 .(C)$ Mutants display substantial hyperactivity in the open field. $(D)$ Hang wire exam reveals reduced grip strength. (E) Layer-specific immunostaining shows significantly reduced upper cortical layers, however normal layering is maintained ( $n=3$ per group). ( $F$ ) The CC is thinner and smaller in the rostro-caudal dimension (red arrow, also cf. in $G$ ) and the DG lacks the lower blade (arrowhead). $(G)$ Coronal sections show normal ventricles and absence of the anterior commissure (arrowheads). ( $n=$ animal number in bars, mean \pm SEM, $t$-test.)

normally. Additionally mutants showed a remarkable hyperactivity. Behavioral examination in the open field test showed their substantially increased exploratory behavior (Fig. 1C). Similar to hypotonia in Tbr2-deficient humans, mutant mice display significantly reduced grip strength (Fig. 1D).

Gross examination of mutant brains showed a markedly reduced brain size (Fig. 1A). In contrast, mutant body weight was normal (Fig. 1B). The size of the cortex and the olfactory bulbs (OBs) was markedly reduced. These differences were detectable at birth, suggesting Tbr2 requirements during embryonic neurogenesis (Fig. 1B).

Histological examination revealed several morphological defects. Mutants displayed a reduction in cortical thickness. Analysis with layer-specific markers Cux1 (layers II-IV), ER81 (V), and Foxp2 (VI) demonstrates that upper-layer thickness is reduced (Fig. 1E). Consistent with reduced upper cortical layers as the principal source of callosal projection neurons (Jensen and Altman 1982), the CC was smaller (Fig. 1F,G). Furthermore, the contralateral projecting fibers from olfactory nuclei and temporal lobes (Zhou et al. 2008), which form the anterior commissure, were absent (Fig. 1G). In the hippocampal dentate gyrus (DG) the suprapyramidal but not the infrapyramidal blade developed (Figs. 1G, 5 [below]). In addition, the mutant OB lacked the characteristic mitral cell layer (Supplemental Fig. 2).

To further explore these abnormalities, we analyzed proliferation, apoptosis, and migration during cortical development. Proliferation of VZ and SVZ cortical progenitors was evaluated by phosphohistone $\mathrm{H} 3(\mathrm{pH} 3)$ immunoreactivity. The number of dividing cells at the ven- tricular surface was normal. However, a significant decrease of nonventricular surface (nVS) proliferation suggested mutants display reduced SVZ neurogenesis (Fig. 2A). To test whether the reduced number of $n V S$ mitosis is due to prolonged cell cycle of SVZ progenitors or reduced production of IPCs in the VZ, we performed BrdU, Ki67 double-labeling (Chenn and Walsh 2002). Following a 30-min BrdU pulse to label S-phase cells, we performed double-immunostaining for pan-proliferation marker Ki67 and BrdU, consistent with a reduced number of abventricular $\mathrm{pH} 3^{+}$cells, we found significantly reduced numbers of $\mathrm{Ki} 67^{+}$cells in the mutant SVZ (Fig. 2B). However, there were no significant differences in the ratio of $\mathrm{BrdU}^{+}, \mathrm{Ki} 67^{+}$double-labeled cells over total $\mathrm{Ki} 67^{+}$cells, indicating that SVZ precursors cycle at similar rates (Fig. 2B). To test whether Tbr2 might be required for the generation of IPCs we examined cell cycle re-entry at E16 after pulse labeling with BrdU $24 \mathrm{~h}$ earlier. Cells remaining in the cell cycle were identified as $\mathrm{BrdU}^{+}$and $\mathrm{Ki} 7^{+}$double-labeled (see the Materials and Methods). The ratio of $\mathrm{Ki} 7^{+}, \mathrm{BrdU}^{+}$double-labeled cells over total $\mathrm{BrdU}^{+}$ cells in mutants was significantly decreased (Fig. 2C), indicating reduced cell cycle commitment.

To evaluate whether increased apoptosis contributes to the reduced brain size, caspase 3 activity was analyzed at E15. There was no evidence for enhanced cell death in the mutant cortex (Fig. 2D).

Next we explored potential migration deficits. We found normal Reelin staining, suggesting normal positioning and function of Cajal-Retzius cells; furthermore, Calretinin staining showed normal preplate splitting. Expression of $\mathrm{mDAB} 1$ and $\mathrm{p} 35$, genes with key roles in neuronal migration (Ayala et al. 2007), did not reveal abnormalities (Supplemental Fig. 4). Thus, correct laminar position of cortical neurons and normal expression of developmental markers suggest that Tbr2 inactivation does not overtly affect cortical neuronal migration, consistent with the observed down-regulation of Tbr2 in migrating neurons (Englund et al. 2005).

To explore whether Tbr2 deficiency impacts more specifically on neurogenesis in the cortical SVZ, we examined the expression of Pax6, marking RGs in the VZ, and the SVZ marker genes Svet1 and Cux2. Pax6 expression in the cortical VZ was unaffected, suggesting normal development of VZ progenitors (Fig. 3A). Likewise, expression of Pax6 at later stages and additional VZ progenitor markers (Hes5, Sox2) was normal (Supplemental Fig. $3 \mathrm{~A})$. In contrast, expression of Svet1 and Cux2 showed a severe and disproportional reduction with respect to the $\sim 25 \%$ decrease of proliferating cells in the mutant SVZ (Fig. 3A). This does not simply reflect a developmental delay since similar observations were made at later stages (Supplemental Fig. 3B).

Consistent with decreased IPC proliferation, NeuroD and Tbrl staining revealed reduced numbers of newly formed neurons (Fig. 3B).

To analyze neurogenesis independently from marker expression, we performed birthdating experiments by injecting BrdU at E16 and analyzing the number of BrdU ${ }^{+}$ neurons at postnatal day 10 (P10), when neuronal migration is largely completed. The number of $\mathrm{BrdU}^{+}$cells was significantly reduced in mutant upper cortical layers, but as judged by correct laminar positions of $\mathrm{BrdU}^{+}$cells, neuronal migration is unaffected (Fig. 3C).

Does transient Tbr2 expression in IPCs also direct the differentiation of their neuronal progeny? Expression of 
Satb2, known to be required for specification of upper-layer neurons (Britanova et al. 2008), is substantially reduced in mutants (Fig. 4A). Intriguingly, expression of Brn2 (Sugitani et al. 2002) was markedly reduced specifically in upper cortical layers II/III, while expression in layer $\mathrm{V}$ was unperturbed (Fig. 4B). Similarly, expression of lower cortical layer markers Ctip2, ER81 (layer V), Otx1 (layers V and VI), and Nurr1 (layer VIb) (Fig. 4C,D; data not shown) did not reveal differences. As judged by expression of the pan-neuronal markers NeuN (Fig. 4E) and MAP-2 (Supplemental Fig. 5), loss of Tbr2 does not simply cause a general delay in neuronal differentiation. Normal immunostaining with SMI-32, MAP-2, and Golgi impregnation shows that the reduced cortical size is not associated with gross abnormalities in dendritic arborization (Supplemental Fig. 5). The smaller size of the CC, delayed differentiation of upper cortical layer neurons, and CC agenesis in Tbr2-deficient humans led us to investigate potential abnormalities of interhemispheric connections. DiI tracing experiments reveal Probst bundles in the mutants (Fig. 4F). Thus, a fraction of callosal axons are misrouted. Collectively, our experiments demonstrate that transient Tbr2 expression is required for normal differentiation of upper cortical layer neurons.

The neuronal differentiation defects prompted us to explore the characteristic somatotopic organization in the Barrel cortex. Using either serotonin transporter (5HTT/SERT) immunohistochemistry or DiI tracing of thalamic afferents, we detected normal thalamic projection into supragranular layers. However, the typical input-related patterning was strongly diminished (Fig. $4 \mathrm{G}, \mathrm{H})$. Bisbenzimide staining also revealed the loss of cytoarchitectonic barrel pattern (Supplemental Fig. 4). Thus, Tbr2 is essential for normal development of peripheral input-related pattern formation and cytoarchitectonic differentiation in layer IV of the somatosensory cortex.

The sequential generation of supra- and infrapyramidal granule neurons in the DG is reminiscent of the neurogenic phases of lower and upper cortical layer neurons in the VZ and SVZ, respectively. Neurons of the suprapyramidal blade are primarily derived from early cell divisions in the dentate neuroepithelium near the ventricle. In contrast, the infrapyramidal blade originates mainly postnatally during a subsequent wave of neurogenesis in the dentate migration stream and hilus (Altman and Bayer 1990). To investigate neurogenesis in the DG, we performed Tbr2, Ki67 double-staining in wild types at P5. Tbr2 shows strongest expression in the dentate migration stream and hilus, and $\sim 66 \pm 7 \%$ $\left(\right.$ mean \pm SD) of Tbr2 $2^{+}$cells $(n=600)$ expressed Ki67 (Fig. $5 \mathrm{~A})$. Conversely, among the population of $\mathrm{Ki}^{+} 7^{+}$cells $(n=606), \sim 52 \pm 14 \%$ were $\mathrm{Tbr} 2^{+}$. In the early postnatal DG substantial gliogenesis occurs concomitantly with the generation of granule neurons (Yuasa 2001). This potentially masks effects of Tbr2 deficiency on proliferation of neuronal precursors in mutants; indeed Ki67 staining was indistinguishable between genotypes (Fig. 5B). Interestingly, immunostaining for activated caspase 3 revealed significantly enhanced cell death in the dentate migration stream (Fig. 5C) that partly explains the substantial reduction of neurogenesis in the mutant dentate migration stream and the hilus as revealed by NeuroD immunostaining (Fig. 5D).

In the adult brain, the DG and the periventricular subependymal zone are the principal sites of neurogenesis. In the mutant DG, the number of $\mathrm{Ki}^{+}$(Fig. 5E) and $\mathrm{BrdU}^{+}$(data not shown) cells was strongly reduced and we never observed newly formed neurons as revealed by Doublecortin (DCX) (Fig. 5F) or Calretinin (data not shown) staining (Kempermann et al. 2004). Interestingly, while neurogenesis in the DG was completely absent, neurogenesis in the subependymal zone of adult mutants appeared normal as revealed by DCX staining in the rostral migratory stream (Fig. 5G). These findings suggest that Tbr2 is developmentally required for establishment of neuronal progenitors in the adult DG but not for the adult subependymal zone.

Finally, we explored Tbr2 contributions to the generation of OB mitral cells. The typical layer of mitral cells, 
normally seen in Nissl staining, was undetectable (Supplemental Fig. 2A). Reelin staining revealed decreased numbers of mitral cells that failed to organize in a single layer and rather appear ectopically scattered (Supplemental Fig. 2B). In DiI tracing experiments, backlabeling of mitral cells from the lateral olfactory tract revealed fewer cells that were not confined to the mitral cell layer (Supplemental Fig. 2C). Anterograde labeling from the OB showed reduced fibers and more diffuse projections into the lateral olfactory tract (Supplemental Fig. 2D).

In summary, we show several critical functions for Tbr2 in cortical neurogenesis. Loss of Tbr2 leads to a reduced number of proliferating cells in the SVZ. Tbr2 is expressed at early stages of IPC development concomitant with progressive down-regulation of Pax6, thus marking the transition from RG to IPC (Englund et al. 2005). The generation of $\mathrm{Tbr}^{+}$progenitors and upper cortical layer neurons is reduced in Pax6-deficient mice
A
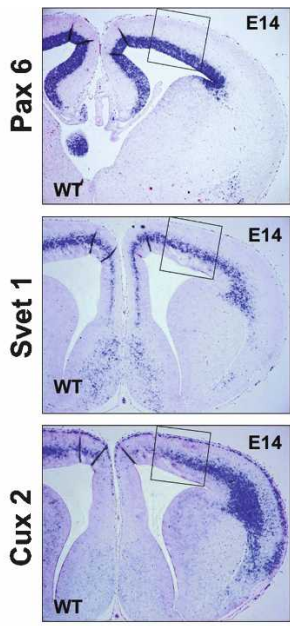

B
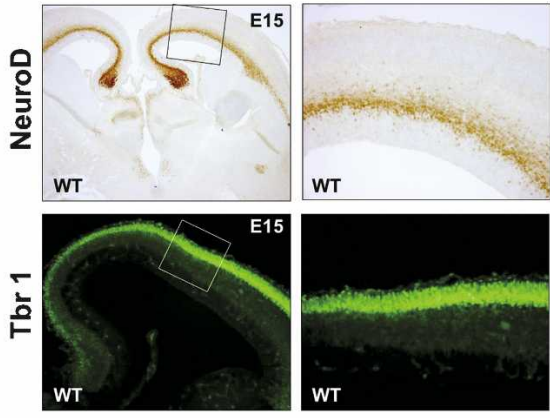

C
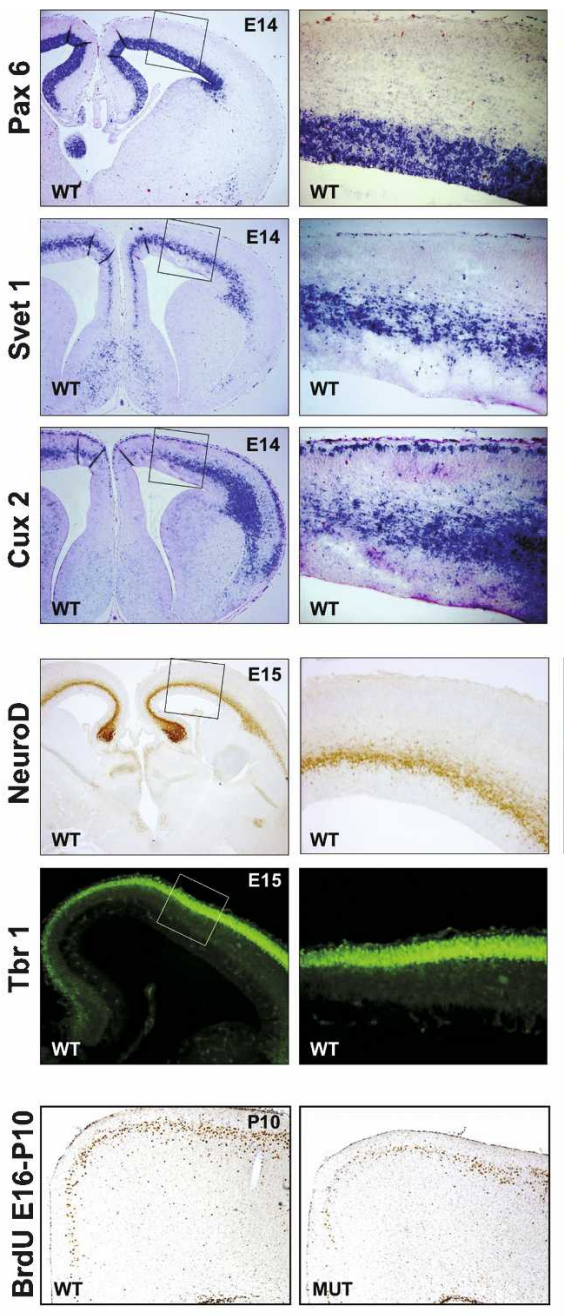

MUT
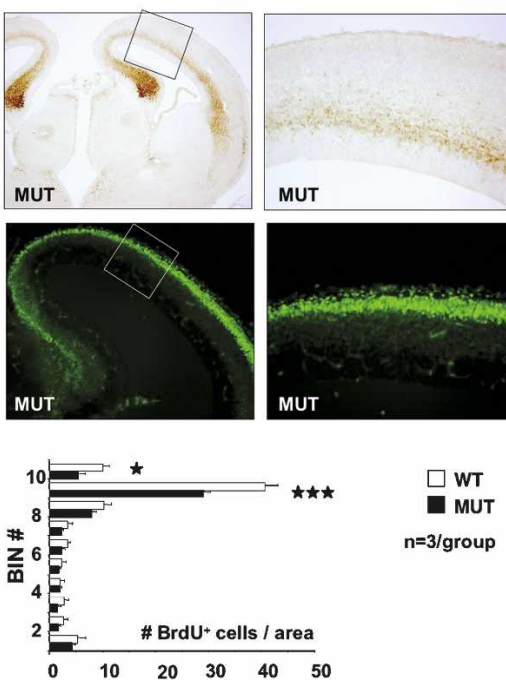

Figure 3. Reduced expression of SVZ markers and decreased neuronal output. $(A)$ In situ hybridization for the VZ marker Pax6 is largely unaffected, whereas expression of the SVZ markers Svet 1 and Cux2 is markedly reduced in Tbr2 mutants. (B) Immunostaining for NeuroD and Tbrl reveals reduced numbers of cortical neurons generated in the mutant cortex. $(C)$ Birthdating experiment of P10 cortical sections showing BrdU-labeled neurons at E16. Generation of upper cortical layer neurons is significantly $\left.\left(\left[{ }^{\star}\right] P<0.05 ;{ }^{\star \star \star \star}\right] P<0.005\right)$ reduced in Tbr2 mutants.
(Tarabykin et al. 2001; Quinn et al. 2007). Similarly, the transcription factor tailless (tlx, alias $\mathrm{Nr} 2 \mathrm{e} 1$ ) is expressed in cortical progenitors slightly earlier than Tbr2, and tlx mutant mice also show a reduced size of the SVZ and specific reduction of upper cortical layers. As for Tbr2 mutants, they also display enhanced aggressiveness and infanticide (Monaghan et al. 1997; Land and Monaghan 2003). Similar to Tbr2-deficient mice, neither of these mutants shows complete loss of SVZ progenitors, suggesting heterogeneous molecular mechanisms for IPC formation. The reduced Svet1 and Cux2 expression levels in Tbr2 mutants are more severe than the reduction of SVZ progenitor numbers. Similarly, the decreased NeuroD expression is more pronounced than the reduction of neuronal numbers deduced from cortical thickness measurements. This suggests that loss of Tbr2 affects the specification of IPCs and the differentiation of their neuronal progeny.

Despite reduced SVZ progenitor numbers, the majority of upper cortical layer neurons form in the absence of Tbr2. Furthermore, the expression of specific neuronal markers (Satb2 and Brn2) appears more affected than others (Cux1 and NeuN). Thus, subprograms of neuronal specification are likely to be differentially regulated by Tbr2. In this context most CC fibers developed and crossed the midline but only a fraction of callosal projections displays pathfinding defects. This is in contrast to the observed CC agenesis in humans (Baala et al. 2007) and might indicate species-specific differences.

In the mutant $\mathrm{OB}$ mitral projection neurons are reduced and their organization and projection disturbed, similar to Tbrl mutant mice (Bulfone et al. 1998), suggesting a lineage relationship with Tbr2. Despite the close similarity of Tbr1 and Tbr2 T-box DNA-binding domains, both family members seem to have evolved for distinct functions in brain development. Indeed the decreased reelin expression, defective preplate splitting, and cortical migration deficits characteristic of Tbr1 mutants are not observed in Tbr2 mutants (Hevner et al. 2001).

Loss of Tbr2 function severely compromises DG development. Enhanced apoptosis in the dentate migration stream contributes to the premature exhaustion of DG neurogenesis and profoundly affects the late developing lower blade. Similar to the neocortex, the substantially reduced NeuroD expression in the developing mutant DG probably reflects Tbr2 requirements during early neuronal differentiation. The reduced numbers of adult DG progenitors implicate Tbr2 functions in both developing and adult progenitor populations. During devel- 
opment Tbr2 is required to establish the pool of adult DG progenitors. Additionally, in the adult DG, Tbr2 expression in IPCs potentially regulates cell cycle re-entry (Hodge et al. 2008). This dual requirement is reminiscent of tlx mutants, which display underdeveloped infrapyramidal blades (Monaghan et al. 1997), while tlx is independently required for adult DG neurogenesis (Shi et al. 2004). Further studies in inducible conditional mutant mice are necessary to rigorously discern Tbr2 functions in DG neurogenesis in the developing and adult brain.

\section{Materials and methods}

For cell cycle length studies, E15 mice were injected with $50 \mathrm{mg} / \mathrm{kg}$ BrdU i.p. and brains were recovered 30 min later. Randomly selected $\mathrm{Ki} 67^{+}$ cells ( $n=1500$ per genotype) in the SVZ were identified; subsequently, BrdU labeling was determined by switching to the corresponding fluorescence channel (Chenn and Walsh 2002). SVZ precursor cells were identified as those set apart from the characteristic dense layer of $\mathrm{BrdU}^{+}$ precursors in the upper VZ as described (Cubelos et al. 2007).

To study cell cycle re-entry, E15 mice were injected with $50 \mathrm{mg} / \mathrm{kg}$ BrdU i.p. and brains were recovered $24 \mathrm{~h}$ later. The interval allows for VZ-derived cells to become Tbr2+ IPCs (Siegenthaler et al. 2008). Randomly selected $\mathrm{BrdU}^{+}$cells ( $n=1500$ per genotype) in the VZ and VZ/ SVZ interface were analysed for Ki67 expression. The SVZ was excluded from the counting frame to minimize contributions of IPC-derived $\mathrm{BrdU}^{+}$ cells, which were in S phase at the time of injection. The boundary was defined by a characteristic band of strongly $\mathrm{BrdU}^{+}$cells due to the 2-h interval of maximum bioavailability of a $50 \mathrm{mg} / \mathrm{kg}$ BrdU pulse (Takahashi et al. 1992) and the typical ellipsoid shape and vertical orientation of VZ nuclei (Takahashi et al. 1995; Calegari et al. 2005).

Additional Materials and Methods are provided as Supplemental Material.

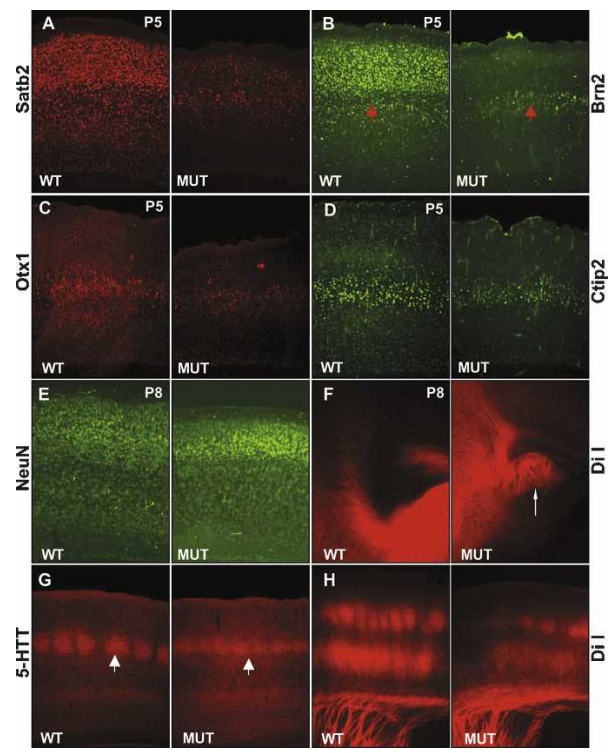

Figure 4. Tbr2 is required for differentiation and functional organization of upper cortical layer neurons. $(A, B)$ Expression of Satb2 $(A)$ and Brn2 $(B)$ in upper cortical layers is reduced, whereas Brn2 in layer $\mathrm{V}$ is maintained (red arrows). $(C, D)$ Expression of lower cortical layer markers Otx1 (layers V, VI) $(C)$ and Ctip2 (layer V) $(D)$ appears unaffected. $(E)$ The reduced expression of upper-layer markers is not due to a general differentiation defect as indicated by normal expression of NeuN. $(F)$ DiI tract tracing of the interhemispheric connections reveals the development of Probst bundles indicative of misrouted callosal axons (arrows). $(G, H)$ 5HTT staining $(G)$ and DiI tracing $(H)$ of thalamo-cortical afferents demonstrate disturbed somatotopic organization of the Barrel cortex (arrows depict an example for the characteristic clustering of thalam-cortical afferents in layer IV).
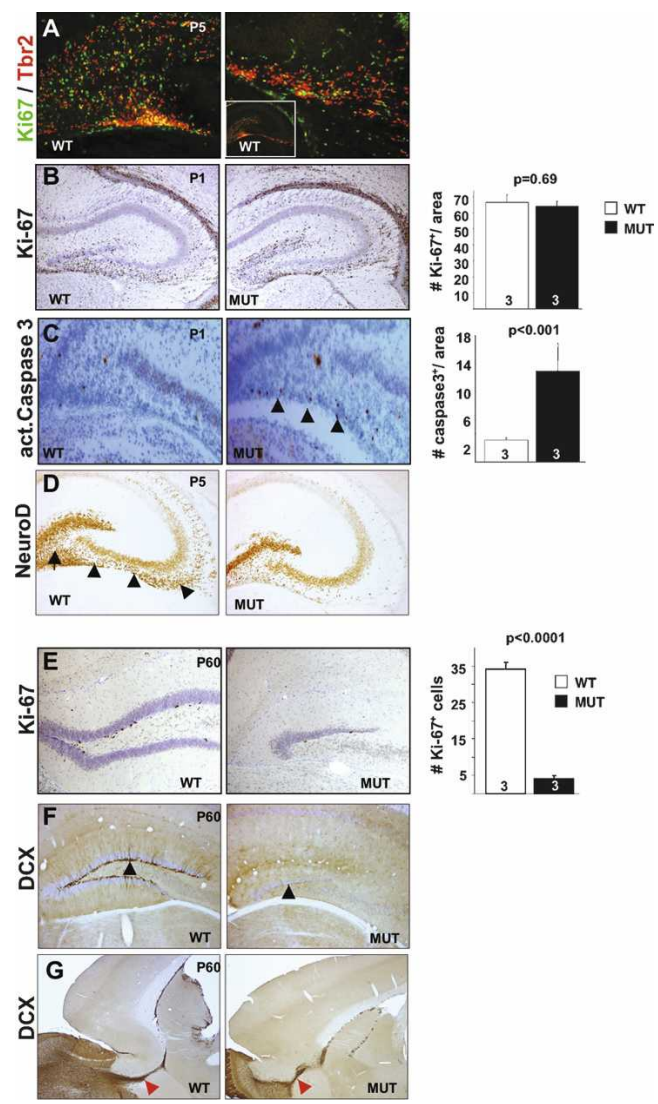

Figure 5. Tbr2 is required for DG development. (A) Tbr2, Ki67 double-labeling at P5 shows Tbr2 expression in progenitors of the dentate migratory stream. Most $\mathrm{Tbr}^{+}$cells are proliferating; however, a substantial fraction of proliferating cells is Tbr2- ${ }^{-}(B)$ Overall the number of Ki $67^{+}$cells in the developing mutant DG is indistinguishable from wild-type littermates. $(C)$ Activated caspase3 staining shows substantially increased apoptosis (arrowheads) in the dentate migration stream and hilus. $(D)$ Neurogenesis in the dentate migration stream is strongly reduced as demonstrated by NeuroD expression (arrow, hilus; arrowheads, migratory stream). (E) The adult mutant DG shows strongly reduced number of Ki $67^{+}$progenitors. $(F)$ DCX staining demonstrates the absence of neurogenesis. $(G)$ In contrast, neurogenesis in the adult SVZ is unaffected. ( $n=$ animal number in bars, mean \pm SEM, $t$-test.)

\section{Acknowledgments}

We thank Drs. T. Noda (RIKEN, Japan), M. Xiang (Rutgers University, New Jersey), and H. Cremer (DBI Marseille, France) for providing in situ hybridization probes, and Dr. V. Tarabykin (MPI Göttingen, Germany) for Satb2 antibody. This work was supported by a Wellcome Trust Programme Grant to E.J.R. S.J.A. is a recipient of a Feodor Lynen-Fellowship from

the Alexander von Humboldt-Foundation, Germany. Z.M. is supported by BBSRC-BB/F003285/1, and A.F.P.C. is supported by MRC grant G0300200 to Z.M. M.G. is supported by a Wellcome Trust Award.

\section{References}

Altman, J. and Bayer, S.A. 1990. Migration and distribution of two populations of hippocampal granule cell precursors during the perinatal and postnatal periods. J. Comp. Neurol. 301: 365-381.

Arnold, S.J., Hofmann, U.K., Bikoff, E.K., and Robertson, E.J. 2008. Pivotal roles for eomesodermin during axis formation, epithelium-tomesenchyme transition and endoderm specification in the mouse. Development 135: 501-511.

Ayala, R., Shu, T., and Tsai, L.H. 2007. Trekking across the brain: The 
journey of neuronal migration. Cell 128: 29-43.

Baala, L., Briault, S., Etchevers, H.C., Laumonnier, F., Natiq, A., Amiel, J., Boddaert, N., Picard, C., Sbiti, A., Asermouh, A., et al. 2007. Homozygous silencing of T-box transcription factor EOMES leads to microcephaly with polymicrogyria and corpus callosum agenesis. Nat. Genet. 39: 454-456.

Britanova, O., de Juan Romero, C., Cheung, A., Kwan, K.Y., Schwark, M., Gyorgy, A., Vogel, T., Akopov, S., Mitkovski, M., Agoston, D., et al. 2008. Satb2 is a postmitotic determinant for upper-layer neuron specification in the neocortex. Neuron 57: 378-392.

Bulfone, A., Wang, F., Hevner, R., Anderson, S., Cutforth, T., Chen, S., Meneses, J., Pedersen, R., Axel, R., and Rubenstein, J.L. 1998. An olfactory sensory map develops in the absence of normal projection neurons or GABAergic interneurons. Neuron 21: 1273-1282.

Bulfone, A., Martinez, S., Marigo, V., Campanella, M., Basile, A., Quaderi, N., Gattuso, C., Rubenstein, J.L., and Ballabio, A. 1999. Expression pattern of the Tbr2 (Eomesodermin) gene during mouse and chick brain development. Mech. Dev. 84: 133-138.

Calegari, F., Haubensak, W., Haffner, C., and Huttner, W.B. 2005. Selective lengthening of the cell cycle in the neurogenic subpopulation of neural progenitor cells during mouse brain development. J. Neurosci. 25: 6533-6538.

Chenn, A. and Walsh, C.A. 2002. Regulation of cerebral cortical size by control of cell cycle exit in neural precursors. Science 297: 365-369.

Cheung, A.F., Pollen, A.A., Tavare, A., DeProto, J., and Molnar, Z. 2007. Comparative aspects of cortical neurogenesis in vertebrates. J. Anat. 211: $164-176$

Cubelos, B., Sebastian-Serrano, A., Kim, S., Moreno-Ortiz, C., Redondo, J.M., Walsh, C.A., and Nieto, M. 2007. Cux-2 controls the proliferation of neuronal intermediate precursors of the cortical subventricular zone. Cereb. Cortex 18: 1758-1770.

Englund, C., Fink, A., Lau, C., Pham, D., Daza, R.A., Bulfone, A., Kowalczyk, T., and Hevner, R.F. 2005. Pax6, Tbr2, and Tbr1 are expressed sequentially by radial glia, intermediate progenitor cells, and postmitotic neurons in developing neocortex. J. Neurosci. 25: 247-251.

Haubensak, W., Attardo, A., Denk, W., and Huttner, W.B. 2004. Neurons arise in the basal neuroepithelium of the early mammalian telencephalon: A major site of neurogenesis. Proc. Nat1. Acad. Sci. 101: 3196-3201.

Hevner, R.F., Shi, L., Justice, N., Hsueh, Y., Sheng, M., Smiga, S., Bulfone, A., Goffinet, A.M., Campagnoni, A.T., and Rubenstein, J.L. 2001 Tbrl regulates differentiation of the preplate and layer 6. Neuron 29: 353-366

Hodge, R.D., Kowalczyk, T.D., Wolf, S.A., Encinas, J.M., Rippey, C., Enikolopov, G., Kempermann, G., and Hevner, R.F. 2008. Intermediate progenitors in adult hippocampal neurogenesis: $\mathrm{Tbr} 2$ expression and coordinate regulation of neuronal output. J. Neurosci. 28: 37073717.

Jensen, K.F. and Altman, J. 1982. The contribution of late-generated neurons to the callosal projection in rat: A study with prenatal x-irradiation. J. Comp. Neurol. 209: 113-122.

Kempermann, G., Jessberger, S., Steiner, B., and Kronenberg, G. 2004. Milestones of neuronal development in the adult hippocampus. Trends Neurosci. 27: 447-452.

Kriegstein, A., Noctor, S., and Martinez-Cerdeno, V. 2006. Patterns of neural stem and progenitor cell division may underlie evolutionary cortical expansion. Nat. Rev. Neurosci. 7: 883-890.

Land, P.W. and Monaghan, A.P. 2003. Expression of the transcription factor, tailless, is required for formation of superficial cortical layers. Cereb. Cortex 13: 921-931.

Molyneaux, B.J., Arlotta, P., Menezes, J.R., and Macklis, J.D. 2007. Neuronal subtype specification in the cerebral cortex. Nat. Rev. Neurosci. 8: $427-437$.

Monaghan, A.P., Bock, D., Gass, P., Schwager, A., Wolfer, D.P., Lipp, H.P., and Schutz, G. 1997. Defective limbic system in mice lacking the tailless gene. Nature 390: 515-517.

Noctor, S.C., Martinez-Cerdeno, V., Ivic, L., and Kriegstein, A.R. 2004. Cortical neurons arise in symmetric and asymmetric division zones and migrate through specific phases. Nat. Neurosci. 7: 136-144.

Quinn, J.C., Molinek, M., Martynoga, B.S., Zaki, P.A., Faedo, A., Bulfone, A., Hevner, R.F., West, J.D., and Price, D.J. 2007. Pax6 controls cerebral cortical cell number by regulating exit from the cell cycle and specifies cortical cell identity by a cell autonomous mechanism. Dev.
Biol. 302: 50-65.

Rakic, P. 1974. Neurons in rhesus monkey visual cortex: Systematic relation between time of origin and eventual disposition. Science 183: 425-427.

Russ, A.P., Wattler, S., Colledge, W.H., Aparicio, S.A., Carlton, M.B., Pearce, J.J., Barton, S.C., Surani, M.A., Ryan, K., Nehls, M.C., et al 2000. Eomesodermin is required for mouse trophoblast development and mesoderm formation. Nature 404: 95-99.

Shi, Y., Chichung Lie, D., Taupin, P., Nakashima, K., Ray, J., Yu, R.T., Gage, F.H., and Evans, R.M. 2004. Expression and function of orphan nuclear receptor TLX in adult neural stem cells. Nature 427: 78-83.

Siegenthaler, J.A., Tremper-Wells, B.A., and Miller, M.W. 2008. Foxg1 haploinsufficiency reduces the population of cortical intermediate progenitor cells: Effect of increased p21 expression. Cereb. Cortex 18: $1865-1875$.

Smart, I.H., Dehay, C., Giroud, P., Berland, M., and Kennedy, H. 2002. Unique morphological features of the proliferative zones and postmitotic compartments of the neural epithelium giving rise to striate and extrastriate cortex in the monkey. Cereb. Cortex 12: 37-53.

Sugitani, Y., Nakai, S., Minowa, O., Nishi, M., Jishage, K., Kawano, H., Mori, K., Ogawa, M., and Noda, T. 2002. Brn-1 and Brn-2 share crucial roles in the production and positioning of mouse neocortical neurons. Genes \& Dev. 16: 1760-1765.

Takahashi, T., Nowakowski, R.S., and Caviness Jr., V.S. 1992. BUdR as an S-phase marker for quantitative studies of cytokinetic behaviour in the murine cerebral ventricular zone. J. Neurocytol. 21: 185-197.

Takahashi, T., Nowakowski, R.S., and Caviness Jr., V.S. 1995. Early ontogeny of the secondary proliferative population of the embryonic murine cerebral wall. J. Neurosci. 15: 6058-6068.

Takashima, Y., Era, T., Nakao, K., Kondo, S., Kasuga, M., Smith, A.G., and Nishikawa, S. 2007. Neuroepithelial cells supply an initial transient wave of MSC differentiation. Cell 129: 1377-1388.

Tarabykin, V., Stoykova, A., Usman, N., and Gruss, P. 2001. Cortical upper layer neurons derive from the subventricular zone as indicated by Svet1 gene expression. Development 128: 1983-1993.

Wu, S.X., Goebbels, S., Nakamura, K., Nakamura, K., Kometani, K., Minato, N., Kaneko, T., Nave, K.A., and Tamamaki, N. 2005. Pyramidal neurons of upper cortical layers generated by NEX-positive progenitor cells in the subventricular zone. Proc. Nat1. Acad. Sci. 102: $17172-17177$.

Yuasa, S. 2001. Development of astrocytes in the mouse hippocampus as tracked by tenascin-C gene expression. Arch. Histol. Cytol. 64: 149158

Zhou, L., Bar, I., Achouri, Y., Campbell, K., De Backer, O., Hebert, J.M., Jones, K., Kessaris, N., de Rouvroit, C.L., O'Leary, D., et al. 2008 Early forebrain wiring: Genetic dissection using conditional Celsr3 mutant mice. Science 320: 946-949.

Zimmer, C., Tiveron, M.C., Bodmer, R., and Cremer, H. 2004. Dynamics of Cux2 expression suggests that an early pool of SVZ precursors is fated to become upper cortical layer neurons. Cereb. Cortex 14: 14081420 . 


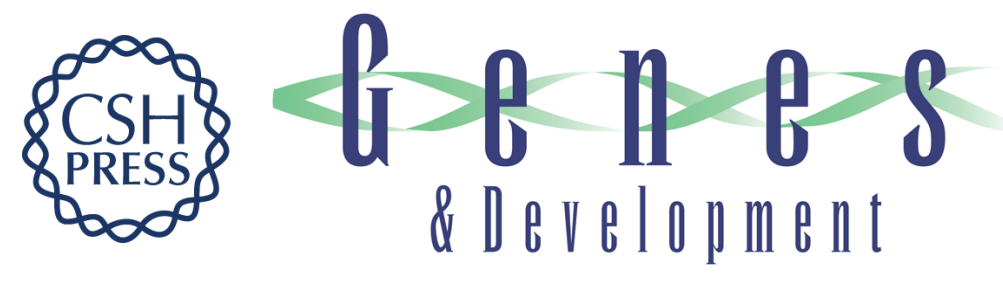

\section{The T-box transcription factor Eomes/Tbr2 regulates neurogenesis in the cortical subventricular zone}

Sebastian J. Arnold, Guo-Jen Huang, Amanda F.P. Cheung, et al.

Genes Dev. 2008, 22:

Access the most recent version at doi:10.1101/gad.475408

Supplemental http://genesdev.cshlp.org/content/suppl/2008/09/16/22.18.2479.DC1
Material

References This article cites 37 articles, 12 of which can be accessed free at: http://genesdev.cshlp.org/content/22/18/2479.full.html\#ref-list-1

License

Email Alerting

Receive free email alerts when new articles cite this article - sign up in the box at the top

Service

right corner of the article or click here.

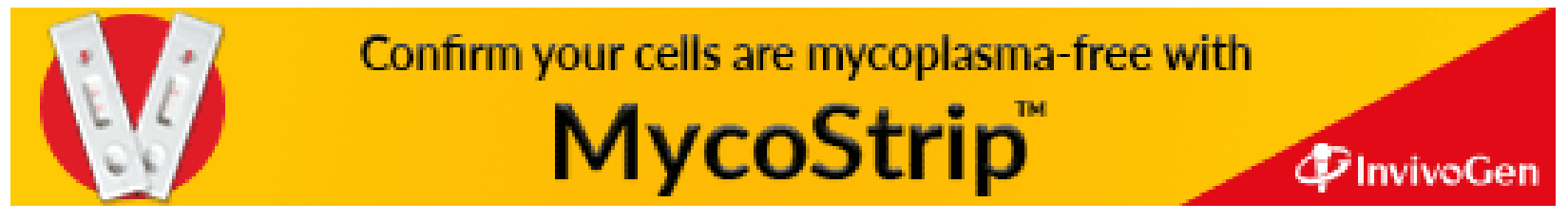

